\title{
Stimulating Savings: An Analysis of Cash Handouts in Australia and the United States
}

\author{
Sinclair Davidson and Ashton de Silva ${ }^{1}$
}

\section{Abstract}

At the onset of the Global Financial Crisis governments around the world implemented fiscal stimulus packages. A key component of many of these packages was aimed at stimulating consumer spending. In Australia and the United States, for example, households received one-off cash payments. We assess the changes in the macroeconomic levels of consumption and savings of both countries coinciding with the timing of the household bonuses using an econometric time series method known as seemingly unrelated time-series equations. The results suggest that the one-off cash bonuses did not stimulate consumption. On the contrary, the evidence suggests savings was stimulated.

\section{Introduction}

The Global Financial Crisis (GFC) began in mid-2007, peaking in 2009. In that time a massive economic dislocation occurred around the world, but largely centred on North America and Western Europe. The causes and consequences of the GFC will be debated for decades. In this paper we examine the fiscal response to the GFC in two economies; Australia and the United States. In contrast to typical approaches we provide a unique comparison; namely the effectiveness of fiscal policy under different prevailing economic conditions.

It is important to appreciate that although these economies are based on the same economic principles, their size and economic character prior to the GFC differ considerably. Australia is a small open economy whereas the US is the largest open economy in the world. Further, their economic experience during the GFC differs considerably. Specifically, the United States was severely impacted by the crisis, millions of individuals lost their jobs and old and venerated financial

1 RMIT University; ashton.desilva@rmit.edu.au. 
institutions were swept away into insolvency. By contrast, Australia weathered the storm reasonably well; not even experiencing two consecutive quarters of negative GDP growth.

The fiscal responses in each economy were similar. Indeed, the Australian government response was predicated on the US experience during the GFC and previous US recessions. Both the Australian government and the US government undertook a series of cash handouts to households (often described as tax refunds), various tax cuts, and spending programs in the hope of maintaining economic activity. The objective, in the language of policymakers, was to substitute public demand for collapsing private demand. In this paper we focus on the cash handouts that occurred in Australia and the US during the GFC. Australian policymakers, for example, had the explicit objective of getting 'the money into the pockets of people who would take it straight to the shops' (Taylor and Uren 2010: 77). This policy, however, appears to the inconsistent with the permanent income hypothesis where a temporary increase in disposable income should have no impact on consumption (Hall 1978).

The Australian experience would suggest that the fiscal interventions were successful. The Economic Security Strategy paid a total of A $\$ 8.7$ billion to households in December 2008, while the Nation Building and Jobs Plan delivered an additional A $\$ 12$ billion to households over March, April and May 2009. The Australian economy avoided two consecutive quarters of negative GDP growth (the local, if somewhat unscientific, definition of a recession). Unemployment did not rise anywhere near the forecast levels (with or without the stimulus packages), whereas in the US unemployment rose beyond forecast levels even with the stimulus packages.

By contrast, the US experience would seem to suggest that the fiscal intervention was unsuccessful. The 2008 Economic Stimulus Act ${ }^{2}$ saw US\$168 billion in tax refunds and the 2009 American Recovery and Reinvestment Act saw an additional US $\$ 288$ billion in tax cuts to business and families (households). Given the deep and prolonged recession in the US and the high levels of unemployment, it seems fair to say the US fiscal policy response to the GFC failed. Perhaps the packages were too small, or poorly implemented, or poorly targeted; all manner of argument can be made and has been made.

We examine aggregate consumption in Australia and the US during the GFC using an econometric time-series technique known as seemingly unrelated timeseries equations. By using this method we are able to construct a counterfactual and so estimate the impact of government measures. Importantly, our analysis does not rely on examining survey data.

2 https://www.govtrack.us/congress/bills/110/hr5140/text. 
In our analysis we consider three important questions: Is there any evidence that household spending increased significantly as a result of the handouts? Conversely, were the handouts saved? Why is it that handouts appeared to 'work' in Australia but not the US? To answer these questions we model consumption, income and savings together with gross domestic product, consumer sentiment, and stock market indices. By using these variables we are effectively examining macroeconomic data for evidence of the permanent income hypothesis (Hall 1978) while taking into account economic conditions. Overall our results are consistent with the permanent income hypothesis.

\section{A review of the literature}

Macroeconomic theory suggests that most of the cash handouts would have been saved rather than being spent. In a Ricardian world, the beneficiaries of the cash handout would realise that their future tax liabilities had increased; they would then increase savings to meet that future cost (Barro 1974). Ricardian equivalence implies that temporary fiscal measures to stimulate the economy should fail.

At the time the Australian policy was formulated, a small literature examining the 2001 US cash handout policy suggested that handouts would be spent, and not saved.

Johnson, Parker and Souleles (2006) had used survey data to examine the effects of the 2001 US cash handout and reported that 20 to 40 per cent of the rebate had been spent over three months and up to two-thirds of the rebate was spent over six months. They interpret these results as being inconsistent with the permanent income hypothesis. By contrast Shapiro and Slemrod (2003), also using survey data, find that the 2001 cash handout was saved. In particular that spending was low relative to economists' expectations.

Agarwal, Liu and Souleles (2007) employ credit card data to analyse the response to the 2001 US tax rebates. They report that consumers initially saved some of the rebate and then increased expenditure: 'For consumers whose most intensively used credit card account is in the sample, spending on that account rose by over $\$ 200$ cumulatively over the nine months after rebate receipt, which represents over 40 per cent of the average household rebate.'

It is interesting to reflect on that statement, 40 per cent of the rebate was spent over nine months. Presumably the other 60 per cent was either saved or consumed via other means. Nonetheless, they too interpret their results as being inconsistent with the permanent income hypothesis. 
The Australian Treasury explicitly relied on an unpublished study by Broda and Parker (2008) as support for its argument that cash handouts would be spent (Uren 2009). ${ }^{3}$ This study investigated the 2008 US $\$ 950$ tax rebate by exploiting timing differentials and comparing spending in those households that had received the rebate to spending in households that were eligible but had not yet received it. Those households that had received the rebate consumed more than those that had not. Broda and Parker had concluded 'the stimulus payments are initially being spent at significant rates'. Yet, on average, only US\$448 was spent in additional purchases, the other 52 per cent of the handout was (at least temporarily) saved. In a later, more complete, paper Broda and Parker (2012) argue that households increased their spending by 10 per cent in the week the cash handout arrived — while that sounds quite large, the US-dollar amount was just $\$ 14$ in that week. Over the next seven weeks US consumers in receipt of the cash handout spent an additional US\$30-50.

In an Australian replication of the Broda and Parker methodology, Aisbett et al. (2012) report that the change in household consumption was less than one per cent, which they describe as being insignificant and quantitatively small.

By contrast Chakrabarti et al. (2011) employ several data resources, including credit card records and household surveys, and show that average consumption decreased while savings increased during and after the 2007 recession.

A reading of the international literature would have suggested to policymakers that there was some scope for demand management policies in countering an economic downturn. Within Australia, for example, policymakers were of the opinion that the permanent income hypothesis was not empirically valid (Taylor and Uren 2010: 74). Olekalns (1997) does report that the permanent income hypothesis is inconsistent with the evidence prior to financial deregulation in the early 1980s, but since that time Australian household behaviour is consistent with the permanent income hypothesis. After the second stimulus package was completed, a survey to determine what had happened to the cash component of the stimulus package was conducted (Leigh 2009). Overall it found that 60 per cent of the cash had been saved or used to pay off debt. Comparing his results to Shapiro and Slemrod (2003), Leigh argued that this was at twice the rate that Americans had spent similar tax rebates in 2001.

The difficulty with most of this literature is that it relies on survey instruments and requires respondents to accurately recall, and then accurately disclose

\footnotetext{
3 Interestingly, an investigation by Harris et al. (2002), published in Australia's leading economic journal, seems to have been ignored. Important findings of the investigation include: 'Based on these estimates, a negative shock to the economy that increases consumer pessimism will increase the number of people saving by a considerable proportion...' (pp.219-20) and 'The results suggest that individuals who are pessimistic in their outlook are likely to save more to account for an uncertain future' (p.221), which raises serious doubt as to whether households would actually spend the bonus (or a large portion thereof).
} 
their consumption behaviour. Also problematic is that researchers can never know the counterfactual. What would otherwise have happened? Alternative empirical strategies do exist, but this usually involves estimating the size of various Keynesian-type multipliers. This approach is controversial as it relies heavily on a priori theorising on the size and magnitude of the multipliers (see Auerbach et al. 2010 for a detailed discussion). ${ }^{4}$ In the next section we set out our empirical strategy that does not rely on survey results, or Keynesian multipliers, and does generate a plausible counterfactual.

\section{The econometric method}

The econometric technique we employ is known as Seemingly Unrelated Time Series Equations (SUTSE, Harvey 1989). ${ }^{5}$ The SUTSE approach falls under the umbrella of state space modelling. State space modelling has been used successfully in many areas of economic research. Key examples include Engle and Watson (1987), Aoki (1987), Harvey and Jaeger (1993), Harvey and Koopman (1997), Prioetti et al. (2007), Panher (2007) and de Silva et al. (2009).

If we let $y_{\mathrm{t}}$ denote a collection of variables at time $t$, the multivariate state space formulation can be represented as follows:

$$
\begin{aligned}
& y_{t}=H x_{t}+\varepsilon_{t}, \\
& x_{t}=F x_{t-1}+v_{t},
\end{aligned}
$$

where (1) captures how the observations evolve over time according to the latent trend and seasonal components of each series, specified in $x_{t}$. How these components evolve over time and combine to measure the observations $\left(y_{t}\right)$ is (pre)determined by the $H$ and $F$. In the base form, inter-series associations are modelled through the variance-covariance matrices of the error terms $\varepsilon_{t}$ and $v_{t}$ $\Sigma_{\mathrm{e}}$ and $\Sigma_{\mathrm{v}}$ respectively. Further details of the model specification are contained in Appendix 1.

The motive for using the SUTSE approach in this investigation is threefold. One, it provides the means of modelling the series consistent with the Sims (1980) method; that is, we do not need to impose any prior theoretical restrictions on the model, thus letting the data speak. Two, we can model more than one variable simultaneously. Further, these variables can be modelled 'as is'; that is, we do not need to engage in transformations such as differencing that

\footnotetext{
4 Recent evidence suggests that multipliers with respect to the ARRA are 'modestly' positive (0.52) in the short run and 'modestly' negative (-0.42) in the long run (Drautzburg and Uhlig 2011). Simiarly, Makin and Narayan (2011) suggest that multipliers are close to zero for the Australian context.

5 The model is fitted using the computer package STAMP 8.2 (Koopman et al. 2009).
} 
will necessarily result in changes in interpretation. Finally, the model assumes stochastic time-series characteristics, thus it is flexible enough to account for any variation in the components, such as seasonal factors, over time. This last point is particularly important as it distinguishes it from the typical form of modelling approaches such as ordinary least squares.

The ability to estimate the (latent) trend and seasonal component of a given set of time series is particularly important as it provides the means to be able to assess whether structural changes have occurred in the different components of the economic variables under consideration. Specifically, the employment of the SUTSE formulation allows us to determine whether the time path of the economic variables has significantly altered from its historically defined underlying trend. We do this be testing whether there has been a change in the trajectory of the underlying trend by testing the series for level breaks. A positive (negative) significant level break indicates the level trend has moved up (down). In addition we also identify one-off departures from trend, referred to as impulse breaks.

\section{The US experience}

Figure 1 presents the three time series of interest for the US; consumption, income and savings. ${ }^{6}$ All three variables are available from the Bureau of Economic Analysis (BEA http://www.bea.gov/) and are supplied in seasonally adjusted form only. ${ }^{7}$

Three instances of cash stimulus have occurred in the US since 1985: 2001 Q3 and Q4; 2008 Q2 and Q3; and 2009 Q2. Each of these periods is identified in Figure 1 by the grey shading. ${ }^{8}$

Consumption and income appear to have grown fairly steadily over the period since 2000. Close inspection of the chart reveals that income peaked slightly in 2001 and 2008 corresponding to the periods in which cash handouts occurred. Conversely, consumption does not appear to exhibit any local peaks; however, in recent times it seems to have deviated negatively from its long-run path.

\footnotetext{
6 Savings is a residual term and includes down payment of debt etc.

7 The BEA provides the annualised data at quarterly intervals; thus the data are divided by four to get the approximate seasonally adjusted quarter values. The seasonally adjusted nature of the data does somewhat modify our empirical strategy. The difference being that a seasonal component was not modelled.

8 During 2001 quarters three and four, US households received rebates as part of the Economic Growth and Tax Relief Reconciliation Act of 2001. Rebates were administered on a randomised basis during this period ranging from $\$ 300$ to $\$ 600$ per eligible household. A summary of this package is presented in Johnson, Parker and Souleles (2006).
} 


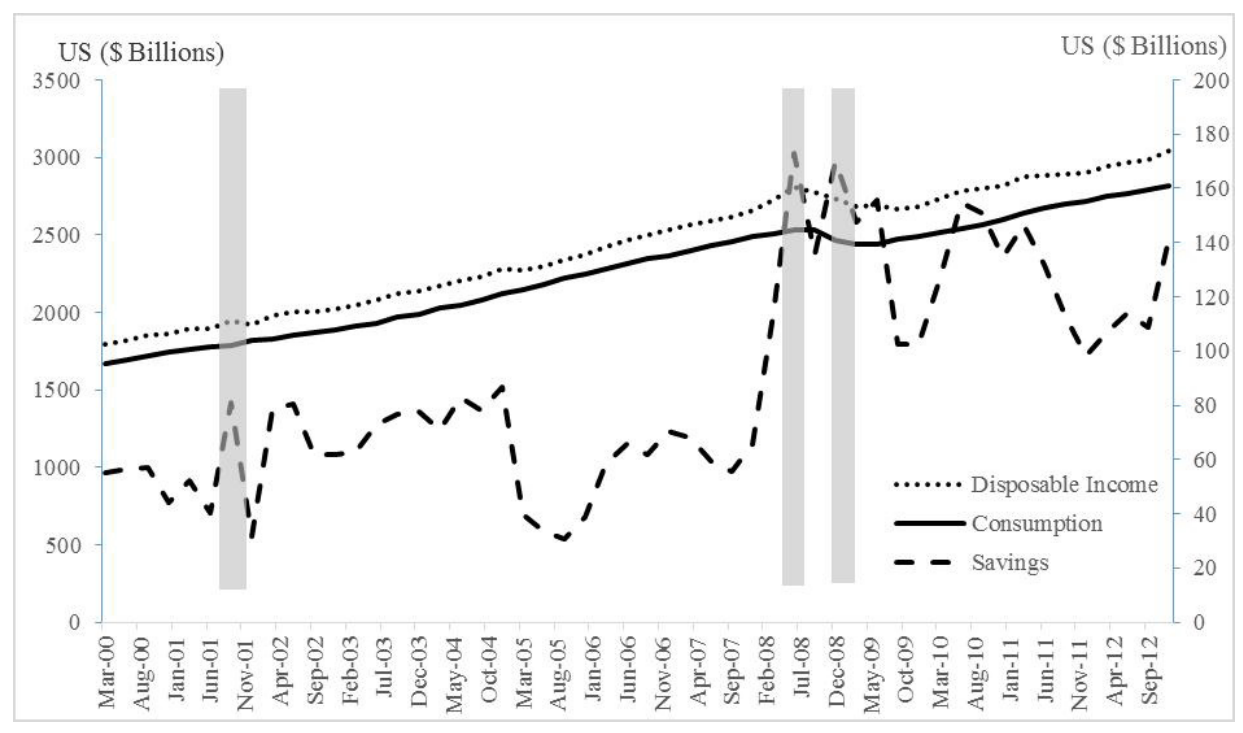

\section{Figure 1: US macroeconomic data}

Source: Authors' calculations; Bureau of Economic Analysis.

Unlike consumption and income, savings is highly volatile and therefore possesses a significant modelling challenge. It appears a number of breaks in the series have occurred. To capture the behaviour of aggregate savings during the period of interest these breaks have to be modelled. An example of a break is the period from 2005 Q1 to 2005 Q4 where the series exhibits a downward shift in the underlying average. Interestingly, periods corresponding to various cash handouts demonstrate positive spikes in saving. Importantly, the SUTSE approach allows us to capture these structural breaks in a straightforward manner.

In addition to the three variables of interest, Gross Domestic Product (GDP), consumer sentiment and the Dow Jones Industrial index were modelled. ${ }^{9}$ The motivation to include these additional control variable stems from the argument that to model the three variables appropriately general macroeconomic conditions also need to be taken into consideration.

To test the effectiveness of the various cash handouts impulse dummies are fitted to the data. An impulse dummy is defined as taking a value of one in the period of interest and zero in all other periods. In addition to these dummies a level break was also tested for in 2009 Q4. By including a level break, we are aiming to determine whether the time path has permanently altered. In summary, the

9 The Dow Jones Industrial Average was sources from DX time series. The consumer sentiment index from the Surveys of Consumers, University of Michigan. 
purpose of fitting these dummies is to determine whether there has been any statistically significant departure from what can be considered as 'normal' or 'baseline' according to the historical properties of the series as determined by the SUTSE formulation and fitting technique.

The key results of our analysis are presented in Table 1 (further results are available upon request in the form of an appendix). These results are based on fitting two models to the natural log of the data spanning 1985 Q1 to 2012 Q4 $(\mathrm{T}=110) .{ }^{10}$ Table 1 is divided into two panels; focus and control variables. The focus variables are those that are of primary interest. The table shows whether deviations from the trend are positive or negative and whether the deviation is statistically significantly different from the trend.

\section{Table 1: Significant departures from trend coinciding with household payments (US)}

\begin{tabular}{|c|c|c|c|c|c|c|}
\hline \multirow{2}{*}{$\begin{array}{l}\text { Date } \\
\text { Year } \\
\text { (Quarter) }\end{array}$} & \multicolumn{2}{|c|}{ Panel A: Focus Variables } & \multicolumn{4}{|c|}{ Panel B: Control Variables } \\
\hline & Consumption & Savings & Sentiment & GDP & Stock Index & $\begin{array}{l}\text { Disposable } \\
\text { Income }\end{array}$ \\
\hline $2001(3)$ & & Positive ${ }^{* * *}$ & & & & \\
\hline $2001(4)$ & & Negative ${ }^{* * *}$ & Negative** & & & Negative ${ }^{* *}$ \\
\hline $2008(1)$ & Negative* & Positive ${ }^{* * *}$ & & Negative ${ }^{* *}$ & Negative ${ }^{* *}$ & \\
\hline $2008(2)$ & Negative ${ }^{* *}$ & Positive ${ }^{* * *}$ & Negative ${ }^{* * *}$ & Negative ${ }^{* *}$ & Negative ${ }^{* *}$ & Positive ${ }^{* * *}$ \\
\hline $2008(3)$ & Negative ${ }^{* * *}$ & Positive ${ }^{* * *}$ & Negative** & Negative ${ }^{* * *}$ & Negative ${ }^{* * *}$ & \\
\hline $2008(4)$ & Negative ${ }^{* * *}$ & Positive $* * *$ & Negative ${ }^{* * *}$ & Negative ${ }^{* * *}$ & Negative ${ }^{* * *}$ & Negative ${ }^{* *}$ \\
\hline $2009(1)$ & Negative ${ }^{* * *}$ & Positive ${ }^{* * *}$ & Negative $* * *$ & Negative ${ }^{* * *}$ & Negative ${ }^{* * *}$ & Negative ${ }^{* * *}$ \\
\hline $2009(2)$ & Negative ${ }^{* * *}$ & Positive ${ }^{* * *}$ & & Negative ${ }^{* * *}$ & Negative ${ }^{* * *}$ & Negative ${ }^{* * *}$ \\
\hline $2009(3)$ & Negative ${ }^{* * *}$ & & & Negative ${ }^{* * *}$ & Negative $*^{* *}$ & Negative*** \\
\hline $\begin{array}{l}2009(4) \\
\text { [Level } \\
\text { Break] }\end{array}$ & Negative $* * *$ & & & Negative $* * *$ & Negative $* * *$ & Negative*** \\
\hline
\end{tabular}

Source: Authors' calculations.

Note: All departures are 'impulse' (one-off) departures except in 2009 quarter 4 where the departure represents a shift in the underlying mean. Blank cells indicate no significant departure. The results relate to two models, each model has one focus variable and the entire set of control variables. Results of control variables are consistent across models. Note, two models were required to avoid problems of multicollinearity between income, consumption and savings. ${ }^{* * *},{ }^{* *} \&{ }^{*}$ denote significance at the 1 per cent, 5 per cent and 10 per cent levels respectively.

After the 2001 cash bonus, Consumption did not deviate from the trend; however, savings did. In 2001 Q3 savings was significantly more Positive than trend, but appears to have been offset immediately in 2001 Q4.

10 Model diagnostics indicate the model fits reasonably well. There does appear to be a hint of autocorrelation in for some of the results - however, we believe our conclusions to be robust with respect to its presence. 
Turning our attention to the most recent episode of household bonuses (together with other Government/Federal Reserve stimuli) we observe a similar but more compelling picture of the ineffectiveness of cash bonuses (and other related macroeconomic measures). In particular, the results in Table 1 indicate that from the period of 2008-09 aggregate Consumption was statistically significantly below trend. Furthermore this 'Consumption gap' - the deviation from trend - has carried through to the end of 2012, as seen in Figure 2.

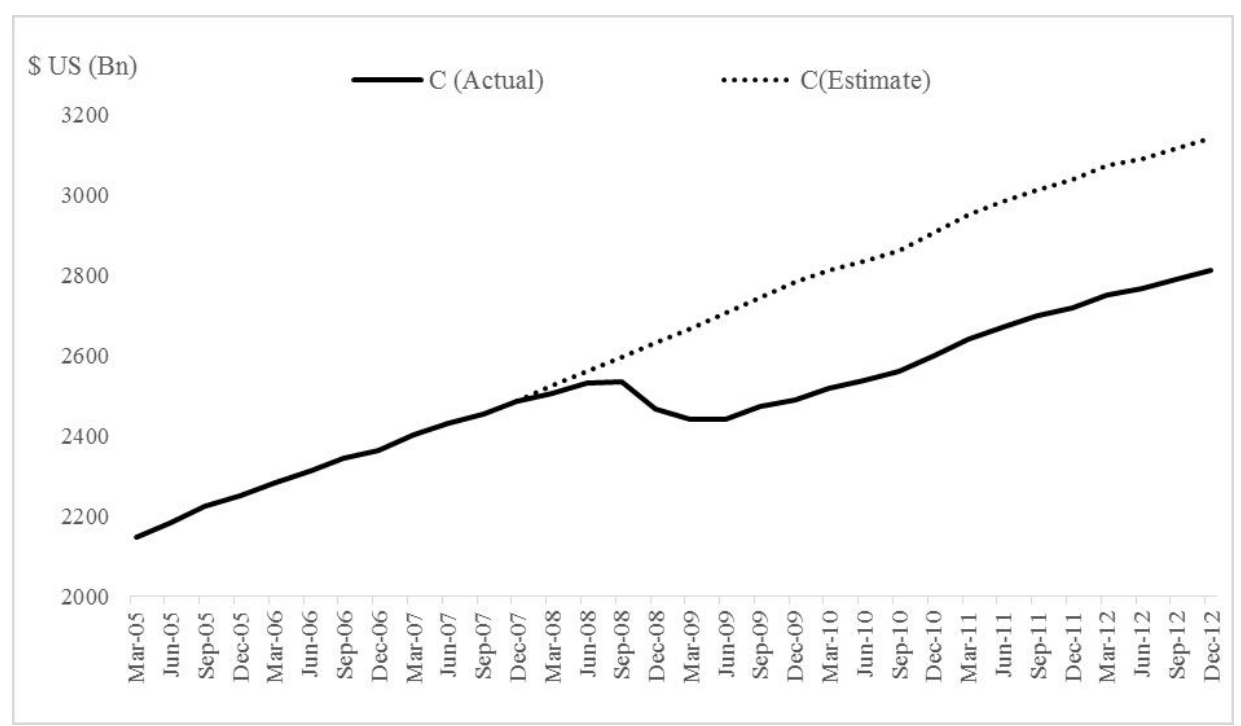

Figure 2: Estimated US consumption gap

Source: Authors' calculations.

In Figure 3, we present the estimated dollar value of the Consumption gap together with the increase in Savings. The increase in Savings corresponds to the cash handouts. The level of Savings, unlike Consumption, does not appear to permanently change in the aftermath of the GFC. Given the significant decreases in GDP, Dow Jones Industrial Index and disposable income, however, it is likely that the return in trend in savings is a result of a deteriorating economy where consumers, in the interests of maintaining a satisfactory lifestyle, are choosing (whether voluntarily or involuntarily) not to save over and above the trend. Our results indicate that households increased their savings in the beginning of 2008, thus suggesting that their precautionary behaviour preceded the more notable events such as the Lehman collapse. 


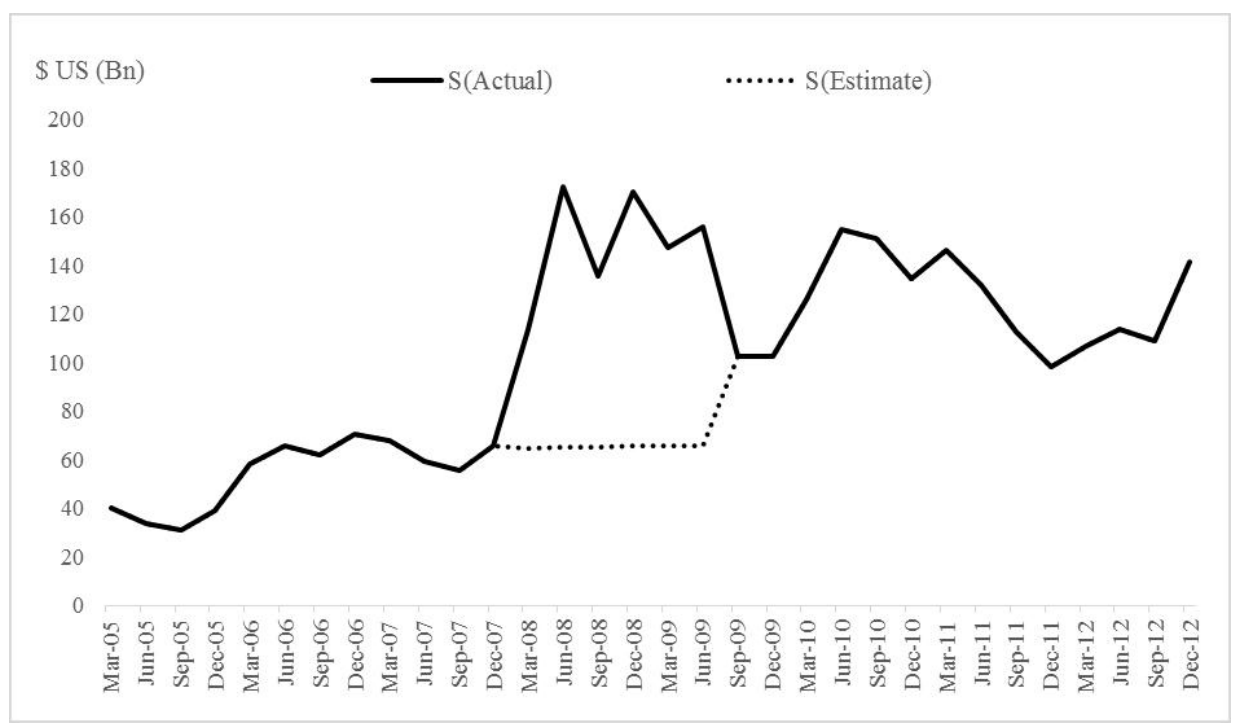

\section{Figure 3: Estimated US consumption gap and savings gap}

Source: Authors' calculations. This gap estimate is calculated from non-annualised rates less the statistically significant deviations.

The scale of the changes in Consumption and Saving are economically significant. The Savings gap, in aggregate is estimated to be $\$ 500$ billion. Using 2006 as the base year, this is equivalent two years' worth of savings. The Consumption gap is estimated to be approximately $\$ 5$ trillion, representing six months' worth of Consumption in 2006 terms.

As a means of verification we test the robustness of these estimates using an ordinary least squares regression. Specifically, we model consumption and savings (separately) as a function of a trend structural break in the intercept at 2008 Q1. It is important to appreciate that this 'benchmark' model is more rigid than the SUTSE specification as the time series components are now necessarily deterministic. ${ }^{11}$ The gap is found to be statistically significant estimated to be seven trillion for consumption and 1.4 trillion for savings. ${ }^{12}$ These estimates are consistent in character; however, we note that OLS model does not represent the data as well and thus conclude that the SUTSE estimates, the more conservative of the two, is more representative of what the US economy has experienced in recent times.

11 The rigidity also means that the OLS estimates should be indicative only as there are patterns in the residuals, thus implying OLS assumptions do not hold.

12 In the savings regression, a shift in the underlying mean (intercept) was found to be significant and permanent. This is in contrast to the SUTSE approach. Over the corresponding six quarters, 2008(1) to 2009(2), OLS and SUTSE estimates are approximately equal at $\$ 500$ billion. 
In summary, the results in Table 1 and Figure 2 suggest that during both rounds of GFC stimulus US households chose to increase Savings rather than increase Consumption. This observation is consistent with the permanent income hypothesis. ${ }^{13}$

\section{The Australian experience}

Once again we focus on the cash handouts administered, of which there were two; one in 2008 Q4 and the second in 2009 Q2.

The analysis begins with a brief discussion of plots of the (household) Gross Disposable Income and Consumption series presented in Figure 4. These data are available on a quarterly basis from the Australian Bureau of Statistics (ABS).

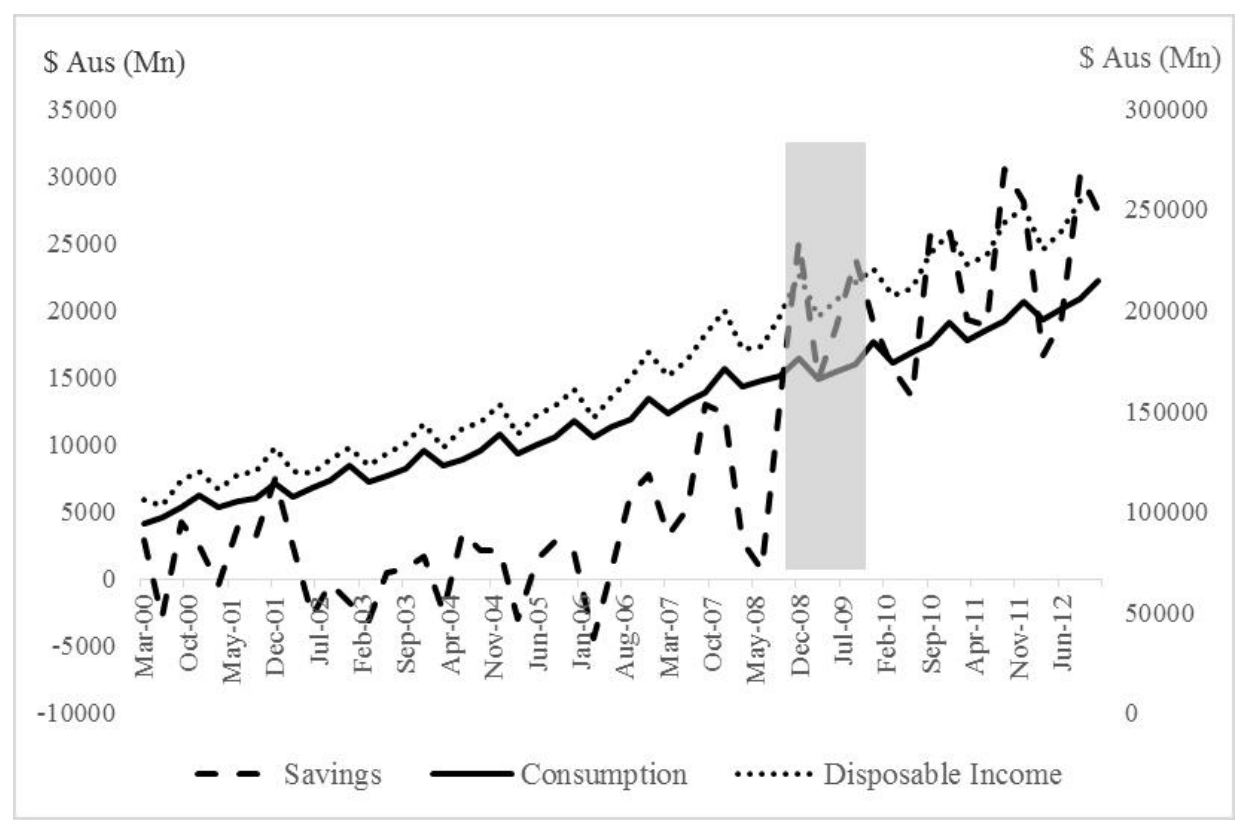

Figure 4: Australian macroeconomic data

Source: ABS National Accounts Cat 5206; left axis corresponds to savings only.

13 This phenomenon is consistent with the economic concept of precautionary savings. Lusardi (1998) and more recently Benito (2006) indicate that precautionary savings increase in times of employment uncertainty. This has been a notable characteristic of the US economy since 2008 Q1 (Chakrabarti et al. 2011). 
In addition to displaying the original data series for Consumption, Income, and Savings, ${ }^{14}$ the chart also identifies periods in which two rounds of cash handouts were administered (2008 Q3 and Q4 and 2009 Q1 and Q2). The Consumption and Income plots do not seem to have deviated from underlying trend at the time the cash handouts were administered.

The apparent insensitivity of Consumption is an interesting phenomenon. In order to further investigate this we ran a third model, employing Food expenditure and Hotel expenditure to proxy non-discretionary and discretionary spending.

The data in this investigation spans 1985 Q1 to 2012 Q4. ${ }^{15}$ Table 2 presents the statistically significant deviations from trend.

Following Table 1, there are two panels in Table 2. The first panel identifies the main variables of interest. The results from three different models are presented in this table, these being Consumption and Savings, modelled separately with the entire set of control variables, and Hotel and Food expenditure modelled together with the control variables.

The first and fourth columns together with Figure 4 tell a similar story to the US experience; namely, that Savings increased at the same time that household cash bonuses were administered. The scale of the increase eclipses the US experience, in aggregate exceeding three times the level of Savings in 2006.

Australian households during and following the onset of the financial crisis have consumed less according to the model estimates. The scale of difference is on par with the US experience, representing 40 per cent of total consumption in 2006 terms. An interesting extension of this finding is to consider whether this has been uniform across consumption categories. The middle two columns of Table 2 panel 1 show that this is not the case. Noticeably, non-discretionary spending only departed from the trend once during the financial crisis, in aggregate representing an economically negligible 1 per cent in 2006 terms. Discretionary spending, however, seems to have permanently underperformed according to model estimates. In 2006 terms it represents a decrease of approximately 16 per cent.

Panel 2 of Tables 1 and 2 look remarkably similar, suggesting that both economies began experiencing a noticeable economic downturn prior to the administration of the cash bonuses and the stimulus packages. Importantly, the results in both tables also demonstrate that this downward course has not been reversed.

14 Savings is a residual term and includes down payment of debt etc.

15 Unlike the US data the Australian data are not seasonally adjusted. Savings is mean adjusted to address the mathematical problem of taking logs of negative values. Further there does appear to be a hint of autocorrelation for some of the results - however, we believe our conclusions to be robust with the respect 

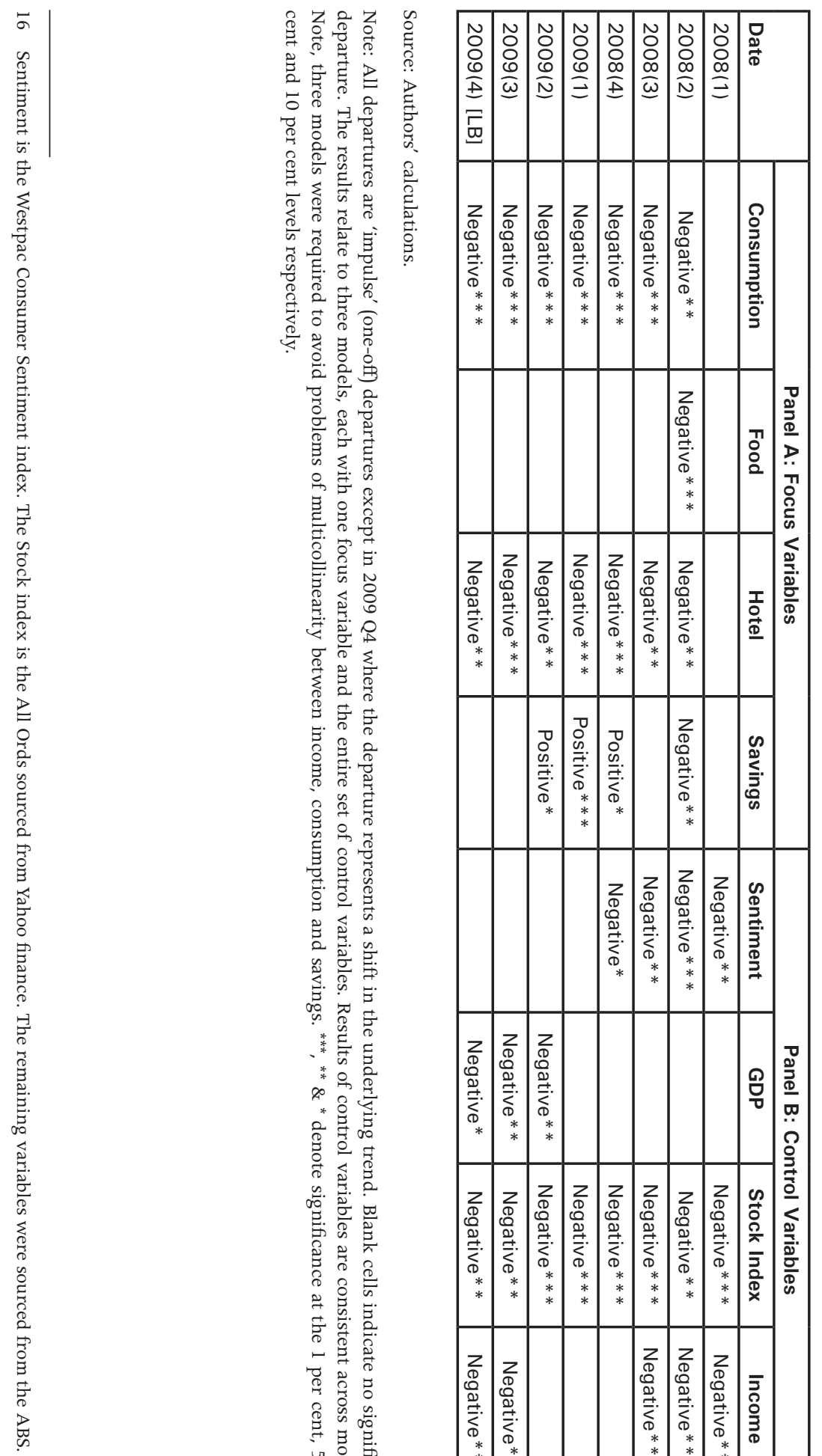

范.

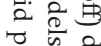

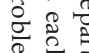

के

s

药

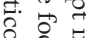

至.

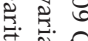

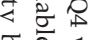

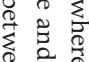

范声

है 8

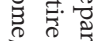

\& $\stackrel{1}{8}$

它

要.

के

$\because \underset{\sim}{\infty}$

论

ड.

要声

絭究

*

* \& 突

음

웅 융

के

产.

实

है

० 8 क

节总.

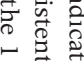

ठี

8 .

品

0
0
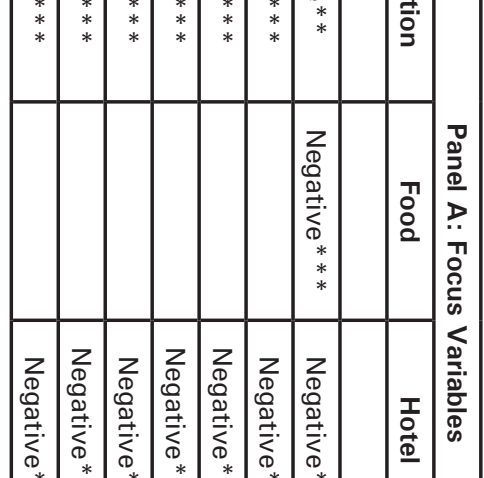

응
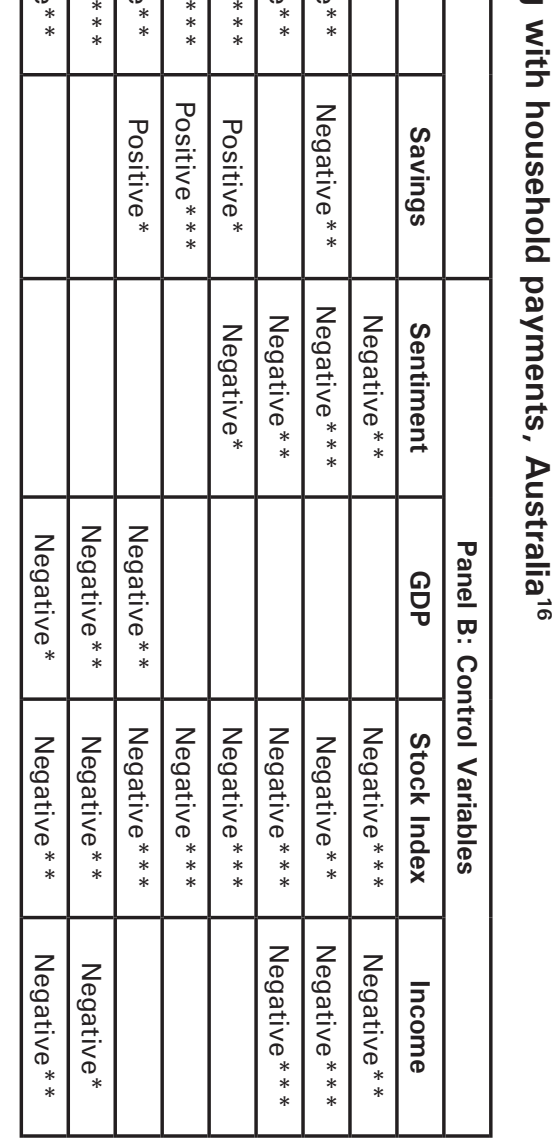


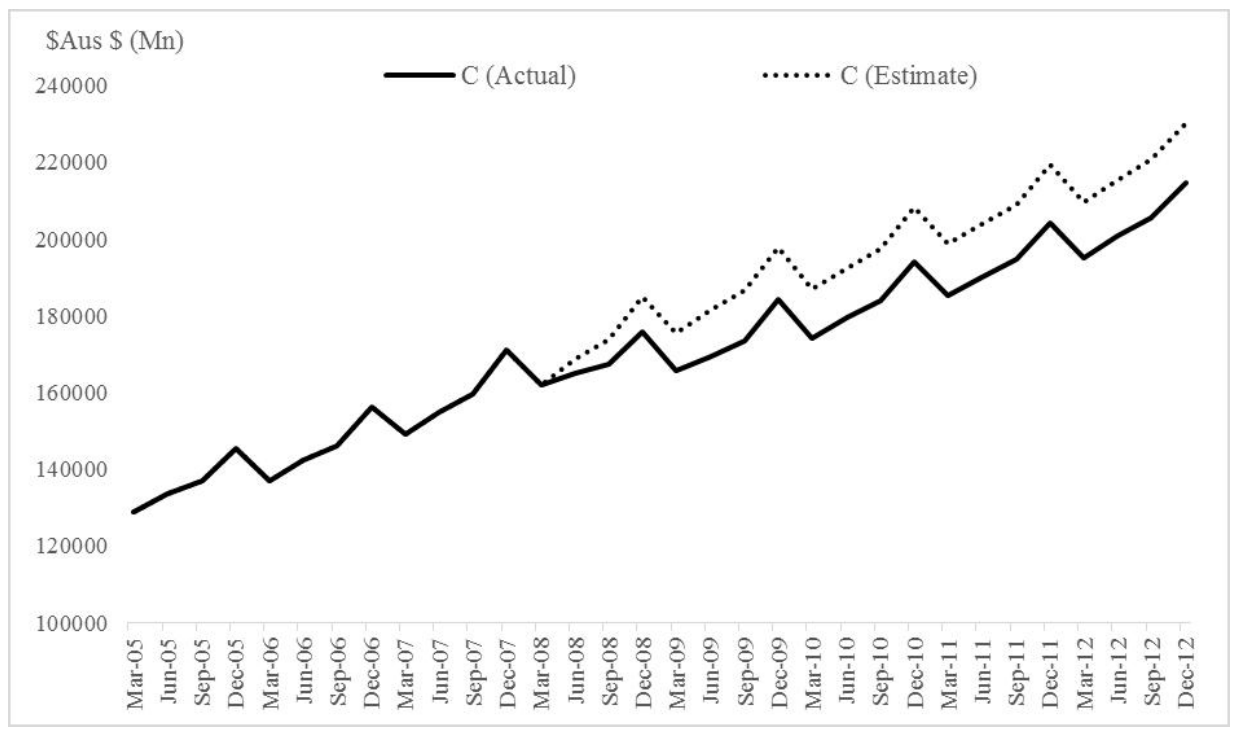

Figure 5: Estimated consumption gap (Australia)

Source: Authors' calculations. This gap estimate is calculated as the actual less the statistically significant deviations.

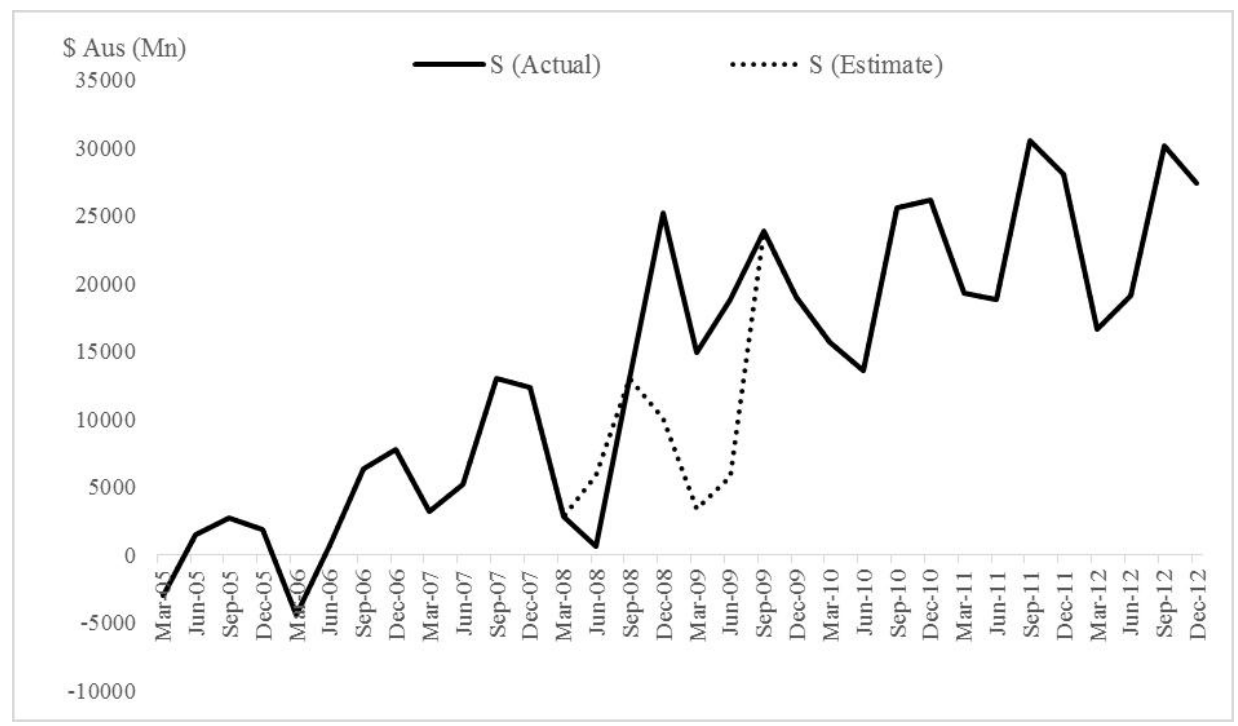

Figure 6: Estimated savings gap (Australia)

Source: Authors' calculations. This gap estimate is calculated as the actual less the statistically significant deviations.

Further, the results in Table 2 and Figures 5 and 6 indicate that Australian households have also behaved consistently with the permanent income hypothesis; that is, they did not increase consumption upon receiving the cash bonuses. 
As before, we examine the veracity of these estimates by comparing them to the results of a comparable standard linear regression approximation. ${ }^{17}$ In the case of the consumption, savings and hotel expenditure the estimates are consistent in direction. ${ }^{18}$ We note that in the case of hotel expenditure the OLS estimated gap is considerably larger by a ratio of approximately five ( 7 billion verses 34 billion). The consumption (240 billion and 165 billion) and savings (35 billion and 57 billion) gaps are broadly consistent for SUTSE and OLS over the corresponding periods respectively. Once again, we consider the gap estimates of SUTSE to be a better representation of the underlying consumption and savings phenomena.

\section{Conclusions}

At the start of this paper three research questions were stated.

Is there any evidence that household spending significantly increased as a result of the cash handouts? Our results suggest there is no evidence that aggregate spending increased. In the US case an economic downturn was not avoided. Our modelling suggests a growing consumption gap consistent with the policy of cash handouts being ineffective.

While Australia did not experience a downturn, the response to the cash handout is very similar. Many advocates of the Australian stimulus package claim this proves that the stimulus package was a success. Our findings, however, suggest otherwise; specifically, Consumption did not increase.

Is there any evidence that the cash handouts (or proportion thereof) was saved? In the case of both economies there is clear evidence that Savings increased. The scale of the 'additional' savings for each economy is significantly large, suggesting that consumers behave cautiously in periods of uncertainty. This is consistent with documented international experience (Nielsen 2010 and IMF 2010).

Why has the stimulus (cash handouts) appeared to have worked in Australia but not in the US? In short, the appearance is a deception. The evidence suggests that in neither economy did the cash handouts increase spending (even after controlling for economic conditions). Further, savings in both economies dramatically increased. Therefore, there must be another reason for the resilience of the Australian economy.

17 OLS regression is fitted using a trend and quarterly dummies. A level break is fitted started in 2008(2) for all series. For all series this was found to be significant at the 5 per cent level. We do note that the OLS model diagnostics do indicate the model is not a good representation of the dynamics of the variables.

18 In the case of Food, a significantly positive shift in expenditure was found to occur. 
In short, our findings suggest both Australian and US consumers acted consistently with the permanent income hypothesis during the time of the crisis. That is, they did not change (increase) their spending behaviour in response to the one-off government handouts.

This is an important conclusion as the results are consistent despite the different economic structure and conditions prior to the onset of the crisis. This suggests that cash bonuses, at least, are ineffective at stimulating the economy.

Limitations to our findings include the fact that the models fitted do not perfectly fit the data. Further, given the sequential nature of break testing, the power of the tests may be compromised. In addition, the a-theoretic approach taken means that we have not explicitly tested the permanent income hypothesis. Despite these limitations we believe our results are robust. Importantly, they are consistent with the conclusions reached in other investigations, including Taylor (2011).

\section{References}

Agarwal, S., Liu, C. and Souleles, N. 2007, 'The Reaction of Consumer Spending and Debt to Tax Rebates — Evidence from Consumer Credit Data', Journal of Political Economy 115: 986-1019.

Aisbett, E., Brueckner, M., Steinhauser, R. and Wilcox, R. 2012, 'Fiscal Stimulus and Household Consumption: Evidence from the 2009 Australian Nation Building and Jobs Plan' (mimeo).

Aoki, M. 1987, State Space Modeling of Time Series, New York: Springer Verlag.

Auerbach, A., Gale, W. and Harris, B. 2010, 'Activist Fiscal Policy', Journal of Economic Perspectives 24(4): 141-164.

Barro, R. 1987, 'Are Government Bonds Net Wealth?', Journal of Political Economy 82: 1095-117.

Benito, A. 2006, 'Does Job insecurity affect household consumption?', Oxford Economic Papers 58: 157-181.

Broda, C. and Parker, J. 2008, 'The Impact of the 2008 Tax Rebate on Consumer Spending: Preliminary Evidence', mimeo University of Chicago, GSB, July.

2012, 'The Economic Stimulus Payments of 2008 and the Aggregate Demand for Consumption' (mimeo, October). 
Chakrabarti, R., Lee, D., Klaauw, W. and Zafar, B. 2011, 'Household Debt and saving during the 2007 recession', National Bureau of Economic Research Working Paper 16999 at: http://www.nber.org/papers/16999.

de Silva, A., Hyndman, R. and Snyder, R. 2009, 'A multivariate innovations state space Beveridge Nelson decomposition', Economic Modelling 26: 1067-74.

Drautzburg, T. and Uhlig, H. 2011, 'Fiscal Stimulus and Distortionary Taxation', Centre for European Economic Research Discussion Paper No. 11-037; at: http://ftp.zew.de/pub/zew-docs/dp/dp1 1037.pdf.

Durbin, J. and Koopman, S. 2001, State Space Modelling, Oxford University Press.

Engle, R. F. and Watson, M. W. 1987, 'The Kalman Filter: Applications to Forecasting and Rational-Expectations Models' in Bewley, T. F. (ed.), Advances in Econometrics, Fifth World Congress.

Hall, R. 1978, 'Stochastic implications of the life-cycle permanent income hypothesis', Journal of Political Economy 86(6): 971-87.

Harris, M. N., Loundes, J. and Webster, E. 2002, 'Determinants of Household Saving in Australia', Economic Record 78: 207-23.

Harvey, A. 1989, Forecasting, Structural Time Series Models and the Kalman Filter, Cambridge: Cambridge University Press.

Harvey, A. and Jaeger, A. 1993, 'Detrending, stylised facts and the business cycle', Journal of Applied Econometrics 8: 231-47.

Harvey, A. and Koopman, S. 1997, 'Multivariate Structural Time Series Model' in Heij, C., Schumacher, H. and Hanzon, B. (eds.), System Dynamics in Economic and Financial Models, John Wiley and Sons: 269-96.

IMF 2010, 'Crisis Alters Pattern of U.S. Consumption' at: http://www.imf.org/ external/pubs/ft/survey/so/2010/res020110a.htm.

Johnson, D., Parker, J. and Souleles, N. 2006, 'Household Expenditure and the Income Tax Rebates of 2001', American Economic Review 96: 1589-610.

Koopman, S., Harvey, A., Doornik, J. and Shephard, N. 2009, Structural Time Series Analyser, Modeller and Predictor (STAMP 8.2), Timberlake Consultants.

Leigh, A. 2009, 'How Much Did the 2009 Fiscal Stimulus Boost Spending? Evidence from a Household Survey', unpublished paper, Research School of Social Sciences Australian National University, at: http://econrsss.anu.edu. $\mathrm{au} / \sim$ aleigh/. 
Lusardi, A. 1998, 'On the Importance of the Precautionary Saving Motive', The American Economic Review 88(2): 449-53, Papers and Proceedings of the Hundred and Tenth Annual Meeting of the American Economic Association.

Makin, A. and Narayan, P. 2011, 'How Potent is Fiscal Policy in Australia', Economic Papers 30(3): 377-85.

Nielson Global 2010, Online Survey 2007-2009, Consumer Confidence.

Olekalns, N. 1997, 'Has Financial Deregulation Revived the Permanent Income/ Life Cycle Hypothesis?', Australian Economic Review 30(2): 155-66.

Panher, G. S. 2007, 'Modelling and controlling monetary and economic identities with constrained state space models', International Statistical Review 75: 150-69.

Proietti, T., Musso, A. and Westermann, T. 2007, 'Estimating potential output and the output gap for the Euro area: a model-based production function approach', Empirical Economics 33: 85-113.

Shapiro, M. and Slemrod, J. 2003, 'Consumer Response to Tax Rebates', American Economic Review 93(1): 381-96.

Sims, Christopher A. 1980, 'Macroeconomics and Reality', Econometrica 48: $1-49$.

Taylor, J. 2011, 'An Empirical Analysis of the Revival of Fiscal Activism in the 2000s', Journal of Economic Literature 49(3): 686-702 at: http:www.aeaweb. org/articles.php?doi=10.1257/jel.49.3.686.

Taylor, L. and Uren, D. 2010, Shitstorm: Inside Labor's Darkest Days, Melbourne University Press, Melbourne.

Uren, D. 2009, 'Cash handouts "likely to be spent, not saved"', The Australian, 10 February. 


\section{Appendix 1: Seemingly unrelated time series equations}

The SUTSE specification used in this investigation has the form:

$$
\begin{aligned}
& \mathbf{y}_{\mathrm{t}}=\boldsymbol{\mu}_{\mathrm{t}}+\gamma_{\mathrm{t}}+\Phi D+\varepsilon_{\mathrm{t}} \\
& \boldsymbol{\mu}_{\mathrm{t}}=\boldsymbol{\mu}_{\mathrm{t}-1}+\boldsymbol{\beta}_{\mathrm{t}-1}+\boldsymbol{\eta}_{\mathrm{t}} \\
& \boldsymbol{\beta}_{\mathrm{t}}=\boldsymbol{\beta}_{\mathrm{t}-1}+\zeta_{\mathrm{t}} \\
& \gamma_{\mathrm{j}, \mathrm{t}}=\cos \lambda_{\mathrm{j}} \gamma_{\mathrm{j}, \mathrm{t}-1}+\sin \lambda_{\mathrm{j}} \gamma *_{\mathrm{j}, \mathrm{t}-1}+\omega_{\mathrm{j}, \mathrm{t}-1} \\
& \gamma *_{\mathrm{j}, \mathrm{t}}=-\sin \lambda_{\mathrm{j}} \gamma_{\mathrm{j}, \mathrm{t}-1}+\cos \lambda_{\mathrm{j}} \gamma *_{\mathrm{j}, \mathrm{t}-1}+\omega_{\mathrm{j}, \mathrm{t}-1}
\end{aligned}
$$

The bolded characters denote $N$-vectors, where $N$ denotes the number of series. In particular, the term $\mathbf{y}_{t}$ denotes a vector of observations at time $t$. The terms, $\boldsymbol{\mu}_{t^{\prime}} \gamma_{t^{\prime}}$ and $\beta_{t}$ denote vectors of trends, seasonals and growth rates at time $t$. The association between the series is captured by the off-diagonal elements of the various $(N \times N) \Sigma$ matrices.

The first equation is often referred to as the observation equation. All the other equations are typically denoted as component equations. The formulation presented above is often referred to as the Basic Structural Model (Harvey 1989). It depicts the trend as being equivalent to a Vector Auto-Regressive Integrated Moving Average $(0,2,2)$. The formulation is easily extended to include a cyclical component. For more information refer to Harvey (1989). 